\title{
O QUE PODE UM ESTÁGIO SUPERVISIONADO COMO MERGULHO NA EXPERIÊNCIA?: VARIAÇÕES NO DISPOSITIVO DIÁRIO DE BORDO
}

\author{
WHAT CAN A SUPERVISED STAGE LIKE DIVING IN EXPERIENCE?: VARIATIONS IN \\ LOG TIME DEVICE
}

\author{
Ana Lúcia Gomes da Silva ${ }^{1}$ \\ Luciano Santos Xavier ${ }^{2}$ \\ Luna Layse Almeida da Silva ${ }^{3}$
}

\begin{abstract}
Resumo: Docente e estagiários, cartógrafos em construção, se dispõem e se desafiam a mergulhar em processos de subjetividades, como exercício cartográfico, desvelando a si mesmos nas relações construídas no Estágio Supervisionado II da graduação em Letras, Língua Portuguesa e Literaturas da Universidade do Estado da Bahia (UNEB), Campus IV, Jacobina/BA. Experiência em que fazem vazar as diferenças nas vozes que emergem e se entrecruzam a partir das narrativas escritas, sentidas e tensionadas pelas palavras, que ganharam corpo e novos sentidos por meio de dispositivos de construção de dados como o diário de bordo. O que aqui apresentamos são os afetamentos e pousos que nos tomam e nos fazem refletir as processualidades em que imergimos, transformando a nós mesmos e também os territórios que habitamos no Estágio Supervisionado, realizado em espaços não escolares da cidade de Jacobina/BA, apresentando outros modos de habitar a docência sempre em devir.
\end{abstract}

Palavras-chave: Estágio Supervisionado; cartografia; subjetividades; diário de bordo; experiência.

Abstract: Teachers and trainees, cartographers under construction, are willing and challenged to immerse themselves in processes of subjectivities, such as cartographic exercise, unveleging themselves in the relationships built in Supervised Internship II of the graduation in Letters, Portuguese Language and Literatures of the State University of Bahia (UNEB), Campus IV, Jacobina/BA. Experience in which they leak the differences in the voices that emerge and intersect from the narratives written, felt and tensioned by words, which have gained body and new meanings through data construction devices such as the logbook. What we present here are the affects and landings that take us and make us reflect the proceduralities in which we immerse ourselves, transforming ourselves and also the territories that we inhabit in the Supervised Internship, held in non-school spaces of the city of Jacobina/BA, presenting other ways of inhabiting teaching always in coming.

Keywords: Supervised Internship; cartography; subjectivities; logbook; experience.

\section{Introdução}

Este texto rastreia vestígios das experiências de Estágio Supervisionado II do Curso de Letras, Língua Portuguesa e Literaturas na Universidade do Estado da Bahia (UNEB) - DCH Campus IV, Jacobina/BA, em espaços não escolares. O objetivo central é narrar essas experiências considerando o dispositivo diário de bordo e suas variações que fazem vazar as diferenças e produzir subjetividades. As regularidades foram facilmente identificadas no dispositivo ao observarem a estrutura física dos ambientes onde iriam realizar os estágios, dos

\footnotetext{
${ }^{1}$ Universidade do Estado da Bahia- UNEB, BA, Brasil.

${ }^{2}$ Universidade do Estado da Bahia- UNEB, BA, Brasil.

${ }^{3}$ Universidade do Estado da Bahia- UNEB, BA, Brasil.
} 
dados quanto à caracterização do bairro, da instituição. De modo mais desafiador, nosso propósito era correlacionar, capturar nas situações efêmeras, imprevistas, circunstanciais e contingenciais das atividades realizadas no Estágio, as produções de subjetividades, as transformações, de modo que ao identificar as regularidades, seus padrões e suas lógicas, também observássemos nas dinâmicas do cotidiano, as complexas e multifacetadas relações não lineares que emergiam no cotidiano dos saberesfazeres dos estudantes e estagiários.

Para tal, as seguintes questões investigativas nos moveram, a fim de problematizarmos o ensino com pesquisa, quais sejam: o que nas práticas pedagógicas instituídas em espaços não formais se configura como segmento endurecido que se torna árvore? $\mathrm{O}$ que nessa mesma árvore segmentada poderia se constituir um rizoma e por que tais transformações ocorrem na/com/pela experiência? Importa aqui salientar que os autores Deleuze e Guattari (1997) apontam que podemos encontrar no rizoma segmentos endurecidos que se tornam árvore, ao mesmo tempo em que na árvore pode se dar a constituição do rizoma, já que ambos possuem tecido duro e flexível.

Objetivamos ainda apresentar traçados do corpo no mergulho da experiência, que se (im)plica, se (des)dobra, se multiplica, exatamente para abarcar a complexidade, zona de indeterminação que a acompanha, colocando problemas, investigando o coletivo de forças em cada situação, esforçando-se para não cair nas armadilhas dos dogmas reducionistas, com sistemas homogeneizadores e hierarquizantes.

A cartografia como metodologia foi utilizada como episteme, modo de conceber o conhecimento, leitura ativa do território habitado; implicação na pesquisa e no encontro do/a pesquisador/a com seu campo, o que significa (re)construir coletivamente o conhecimento e sua inseparabilidade entre pensar e intervir. A cartografia é, pois, da ordem das semioses; semiotiza o mundo através das diversificadas linguagens, com narrativas plurais, artísticas, com instalações e performances que suscitam corpo-vida autoral na experimentação ancorada no real em que lançamos mão, trazemos às mãos, manipulamos matérias e coisas da pesquisa interventiva. Foram guiados por esses pressupostos que na nossa experiência de Estágio Supervisionado, os desenhos, fotografias, artes cênicas, narrativas escritas, oralidades, em multisemioses criativas, fizeram parte dos encontros com as crianças, adolescentes em distintos territórios da cidade de Jacobina, na Bahia.

Assim, ao lançar para a turma de Letras, o convite-desafio com a cartografia como inspiração e atitude epistêmico-metodológica e política, suspeitava como professoraorientadora, fazer aparecer na paisagem-território do Estágio Supervisionado o embate e debate para provocar problematizações e movimentos que se entrecruzam, potencializando linhas de fugas que (re)afirmam, (re)criam as potências da vida como outros modos de habitar a docência, outros modos de pensar e fazer ensino com pesquisa na experiência encarnada na vidaformação, movida pela pergunta lançada à turma no primeiro encontro do semestre de 2019.1: o que pode um Estágio Supervisionado desestabilizar? Como afetar estudantes e convidá-los a habitar outros modos de formação docente? A experiência se dá sempre com o que nos passa, nos toca, nos afeta e pede passagem. E assim nos lançamos nos territórios a serem habitados.

\section{O mergulho na experiência: a invenção de si na partilha com o outro}

A experiência presentifica a narrativa teorizada para observar o que está comunicando; quais aprendizagens suscitaram, compondo a paisagem com os riscos da viagem e do mergulho. Por isso, inclusive, a relação de correspondência que aí se implica não ocorre na similaridade, mas na diferença, no modo como cada sujeito lê e elabora o mundo e se elabora no mundo, se (re)inventa, por meio do Outro e das relações fluidas construídas. Ato intencional e complexo, a experiência é marcada por inúmeros desdobramentos e permeado de desejos e singularidades. 
Nesse sentido, o conceito de experiência ultrapassa todos os limites factuais e concretos; rompe, fragmenta, deixa de ser exclusivamente empírico e se estabelece no ínterim dos processos de reflexão e interpretação da realidade lida e representada, sob a intencionalidade experimentada ou vivida diferentemente por diversos sujeitos, que apresente característica de transformação e marque uma diferença nos sujeitos nos quais ela se dá (ALMEIDA, 2020).

Destacamos ainda ao diálogo Marie-Christine Josso (2007), ao acionarmos no Estágio as narrações centradas na experiência da formação inicial que se reverberam ao longo da vida e revelam formas e sentidos múltiplos de ser-sendo no mundo singular-plural, como modos, criativos e inventivos do pensar, do agir e do viver junto. Um trabalho transformador de si, ligado à narração das histórias de suas formações e sobre elas refletidas. Um trabalho de reflexão a partir da narrativa da formação de si (pensando, sensibilizando-se, imaginando, emocionando-se, apreciando, amando, envergonhando-se, odiando, construindo conexões e afetamentos nos territórios), aportando na experiência a arte da ficção, da inventividade, da música, das artes plásticas, cênicas, decorativas etc. Essas realidades imaginárias e, no entanto, bem concretas, no território habitado, atuaram como fontes de referência para registrar acontecimentos impossíveis de verbalizar.

Assim buscam Luna e Luciano, ao narrarem e se exporem na viagem empreendida, visando um mergulho na/com a experiência para mostrar-nos que compreenderam as centralidades ou os fios condutores do método cartográfico, no ato de produzirem subjetividades, acionando o conceito como poiesis na/com/pela experiência narrada, pelo encontro em movimento que é próprio da processualidade da cartografia, com a investigação de processos em curso. Na medida em que "o cartógrafo se encontra sempre na situação paradoxal de começar pelo meio, entre pulsações” (BARROS E KASTRUP, 2015, p. 58).

A partir desses afetamentos, Luna e Luciano narram os desenhos sociais encontrados nas Organizações Não Governamentais - (ONG's), associações, sindicatos etc., na escola, pelas miudezas e habitação do território, pelos sentidos e pelos corpos agenciados com as crianças e os adolescentes. Deste modo, é importante destacar que, por isso mesmo, os dados na pesquisa cartográfica são compreendidos como matérias, coisas, miudezas, gestos; fotografias, desenhos, riscos, narrativas, vídeos, ações efêmeras e ao mesmo tempo intensas, irrepetíveis, estratégias produzidas com os corpos, olhos, múltiplos sentidos, que ao serem capturadas, trazidas ao olhar, nos convida a enxergar com nosso terceiro olho, com o olhar da sensibilidade aflorada, como veremos a seguir.

\title{
Os dispositivos de construção de dados: a repetição e a variação no diário de bordo
}

Pousamos a atenção nos seguintes trechos das narrativas de Luna e Luciano:

\begin{abstract}
[...] a professora Ana Lúcia ao nos convidar para estudar e experimentar o método cartográfico realizou em sala o estudo em grupo a partir do vídeo sobre o estágio como eixo articulador da licenciatura e como campo de conhecimento e o ensino com pesquisa na formação do professor-pesquisador.
\end{abstract}

Desse trecho emergem as lembranças marcantes das reflexões coletivas, ainda em sala de aula, sobre a urgente percepção de que educadoras e educadores são também pesquisadoras e pesquisadores implicados nas subjetividades dos territórios que habitam. Nas aulas seguintes, nos reorganizamos para a imersão em campo, após ter lido coletivamente, debatido e reescrito o dispositivo Inventário Institucional elou organização social ${ }^{4}$, organizado um mapeamento

\footnotetext{
${ }^{4}$ O Inventário Institucional e/ou organização social foi elaborado baseado[1] no Inventário Educacional da Universidade Federal da Bahia-UFBA, do Curso de Licenciatura em Pedagogia EaD, e se constitui num
} 
dos bairros e divisão dos grupos entre as/os estudantes graduandos do curso de Letras, Língua Portuguesa e Literaturas (UNEB), do $6^{\circ}$ semestre, em 2019.

$\mathrm{Na}$ etapa seguinte, após caracterizar os sujeitos e suas demandas, por meio do inventário, socializamos em sala um mapeamento dos bairros de Jacobina/BA, apresentamos os sujeitos, suas diferenças e singularidades, atravessados pelos marcadores sociais de gênero, raça, classe, geração, etnia, destacando a escuta sensível de suas demandas, a fim de elaborarmos o Projeto didático-pedagógico e que este, atendesse ao coletivo para o qual direcionaríamos nossas ações de Estágio II, em espaço não escolar.

Fomos incitados a operar com o conceito de dispositivo, apresentado através dos movimentos e funções dos dispositivos na prática da cartografia (KASTRUP; BARROS, 2015, p. 76). Ampliamos o estudo com a concepção de dispositivo apresentada por Foucault, como sendo "um conjunto heterogêneo que engloba discursos, instituições, o dito e não dito". Este movimento de compreender o que é um dispositivo também desencadeou o debate, pois queríamos saber como operacionalizar cada dispositivo no estágio. A professora Ana Lúcia destacou que a função-motriz e potência do dispositivo é fazer falar, fazer ver e estabelecer relações, articular a repetição e variação. São estas relações que apresentaremos através do diário de bordo.

Por meio do dispositivo diário de bordo, pudemos vislumbrar além das narrativas registradas, a corporificação das subjetividades dos sujeitos participantes das atividades do Estágio Supervisionado. Os processos de subjetivação foram concebidos nas relações das crianças com as atividades, entre os colegas, comunidade e as suas formas de ver, ser, interpretar e estar no mundo, a partir de relações. O que se percebe, é que no diário há vestígios dos modos de sentir, dizer, possibilitando novas enunciações e subjetivações. Como dispositivo, o diário teve a função de referência, que

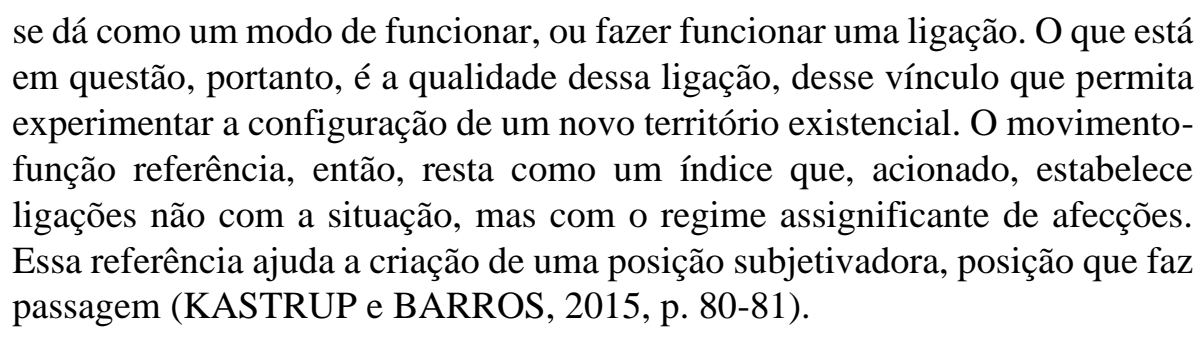

Para a constituição do presente artigo, debruçamo-nos apenas ou principalmente, sobre o diário de bordo/de pesquisa, por ser apresentado como um dos dispositivos da pesquisa imbricado de laços e invenções de si e do outro, ambos tensionados à compreensão das realidades mútuas, as quais estavam imersos tanto os estudantes estagiários, como os sujeitos participantes das atividades realizadas nos territórios.

Nesse sentido, destacamos a relevância do diário de bordo como dispositivo de registro e reflexão dos dados construídos, através da nossa imersão no território cartografado. Assim, o

registro do trabalho de investigação ganha, dessa forma, função de dispositivo, não propriamente para concluir o trabalho ou apresentar seus resultados finais, mas como disparador de desdobramentos da pesquisa. A pesquisa-intervenção requer, por isso mesmo uma política da narratividade (BARROS e PASSOS, 2015, p. 173).

É importante ainda salientar os desafios na constante observação e registro das narrativas e percepções dos/as estagiários, mediante um território cartográfico multifacetado, com

dispositivo de pesquisa para levantamento de dados e registro sistematizado de aspectos materiais ou imateriais de uma determinada instituição ou organização social. 
narrativas distintas, mas que se entrecruzam, quando consideradas as vivências das crianças e adolescentes na instituição e comunidades cartografadas. São vozes e performances de crianças e adolescentes que constantemente demonstram pedidos de atenção, afetos e carinhos, construindo elos muitas vezes improváveis de conseguir serem trazidos em palavras apenas. Estes gestos eram produzidos nas fotografias que faziam, nas selfies, nos desenhos, nos desejos relatados e nas performances artísticas apresentadas.

\section{Narrativas cartografadas: o que pode o Estágio Supervisionado como transversalidade rizomática}

A transversalidade é aqui concebida considerando o que nos apresenta Félix Guattari (1985), como forma de atravessar as relações entre as pessoas, como mobilidade por entre os fios do rizoma, com a finalidade de romper com a hierarquização e produzir conhecimento coletivamente, colocando o rizoma sobre as árvores, a fim de brotar aproximações, vizinhanças conceituais com distintas áreas do conhecimento, a fim de retomarmos a questão inicial deste texto quanto ao que nessa mesma árvore segmentada poderia se constituir um rizoma e por que tais transformações ocorrem na/com/pela experiência das aprendizagens no Estágio não formal?

É com vistas a problematizar, e não a responder as questões apresentadas no início do texto, que apontamos algumas limitações ou mesmo desafios do método cartográfico, a saber: a atenção flutuante (BARROS; KASTRUP, 2015), pois em meio a tantas narrativas e subjetividades, foi bastante desafiador centrar-nos em uma e não em outras. Isto é, o desafio se estabeleceu na definição critérios de percepção do que era posto e narrado, pois o tempo e espaço do estágio não contemplariam a totalidade da compreensão de todas as subjetividades ali expostas, mediante a nossa imersão como estagiários/pesquisadores.

Nessas confluências e emaranhado de atitudes que nos convocavam, é que gradualmente foram construídos pousos. Breves pausas de densa intensidade emotiva, motivadas pelos afetamentos. A menina negra que se olha ao espelho e não se vê como uma criança bonita. Ela sorri envergonhada, leva as mãos ao rosto, como quem se esconde ali na roda que reúne crianças e adolescentes de um lar filantrópico de Jacobina/BA. O garoto que folheia a revista buscando alguém que seja parecido com ele e ao se ver em alguém de pele mais clara, é questionado pelo colega ao lado: "mas esse nem é da tua cor!".

Outras subjetividades produzidas no território habitado também nos projetam aos conflitos dos sujeitos consigo mesmos e com a comunidade em que convive; como no caso da criança "briguenta" e "birrenta", chamava a atenção dos estagiários todos os dias nas atividades, num outro espaço não formal que acolhe jovens do município. Até descobrirmos o âmago de um ser humano que nos apresentava parte de sua crise por ter sido, abandonada pelos pais, tendo a sua criação feita pelas tias, que por mais afeto e inteiro cuidado acionados não substituía a ausência dos pais e deste modo nos apresentava uma pista dos meandros da infância em curso permeada de aflições e desejos de ser vista, de ser acolhida, de modo que o centro das atenções era ela nos encontros do grupo, brigando, falando alto, gesticulando, acionando assim nossa atenção para ela.

Demoramos a compreender a lidar com estes sentimentos que afloravam, mas ao pousarmos a atenção e o olhar para ela de modo mais cuidadoso e afetuoso, com indagações sobre seus desejos, suas ações e sentimentos, as narrativas nos afetaram e nosso sentimento de empatia, nos fez olhar de modo mais humano para ela.

Foram diversas as histórias que se entrecruzaram e atravessaram os olhares estranhos, mas atentos, que foram entremeados no território em que habitamos, sob a ótica dos/as pesquisadores/as imbuída de afetos e cuidados com o outro, na contramão das imposições positivistas anuladoras das relações subjetivas entre o eu e o outro, entre o pesquisador e os 
sujeitos participantes do processo de construção coletiva epistêmica. Deste modo, nossa compreensão acerca da subjetividade é inspirada em Guattari (1992), que a concebe como uma produção individual, coletiva e institucional. Faz crítica à separação do sujeito individual e a sociedade, defendida pelo modelo clássico. Enfatiza que a subjetividade é fabricada não apenas pelas fases psicogenéticas, mas também pelas máquinas sociais e por influências não humanas. Em outras palavras, compreender a mesma em sua virtualidade, em sua dimensão criativa, nos processos individuais e coletivos de agenciamentos.

São nessas escritas emergentes dos diários de bordo que são reveladas narrativas preciosas, a exemplo também da descrição de Luna ao narrar um dos encontros nas primeiras atividades do Estágio:

Fiz dupla com um garoto de 7 anos, que tem quatro irmãos também morando no abrigo. Ele gosta de brincar, viajar, de futebol e sonha em se tornar um cuidador de animais. Carinhoso, me abraçava e também gostou de poder anotar meu nome e o que gosto de fazer. Ele brincava de tentar descobrir as letras das palavras, está em fase de aprender a escrever e se encantar com as possibilidades de se apropriar da escrita. Foi quando percebi que como estagiária, aos poucos senti que os receios começavam a dar lugar às afetividades, de quem escuta, se aproxima, abraça, ri, brinca e tem o desejo de contribuir na formação cidadã e crítica destas crianças. (Diário de bordo, Luna Laís, agosto 2019).

Segundo Barros e Kastrup (2015, p. 70), “podemos dizer que para a cartografia essas anotações colaboram na produção de dados de uma pesquisa e têm a função de transformar observações e frases captadas na experiência de campo em conhecimento e modos de fazer". Isso tensiona o que as autoras chamam de circularidade aberta, em que há a coprodução de experiência em conhecimento e de conhecimento em experiência. Tal circularidade tece uma teia de relações em que os sujeitos do processo cartográfico, isto é, pesquisador/a e participantes, são afetados de modo simultâneo, cada qual à sua intensidade e com vislumbramento do mundo em que participa e o circunda. São as utopias também reveladas, trazendo os sonhos do garoto e da estagiária, tecendo ligações e produzindo desejos.

Os relatos registrados no diário de bordo, e que ultrapassam as linhas escritas no papel para se ater ao ethos do pesquisador, buscam captar e revelar os afetamentos a partir da descrição dos acontecimentos, mas também das impressões do/a pesquisador/a-cartógrafo/a. Luna foi afetada e afetou, criou o ethos da confiança paulatinamente enquanto realizava sua imersão e contato físico e afetivo com as crianças, num movimento corpo-território, corpo autoral no mergulho com a experiência. É nessa teia de relações que os sujeitos se implicam e concebem as subjetividades dialogadas e em conflitos no território, nas atividades propostas, nas relações didáticas e de afetos interpostas ao ato de cartografar.

É também no diário de bordo que são reunidas informações objetivas sobre o espaço em que acontece a atividade, pessoas presentes, o que estava planejado para aquele momento, aquele encontro. Nessa tecitura do texto, surgem paisagens cartográficas, vínculos construídos gradualmente, o envolvimento com os processos, visibilidade das experiências que até podem ter passado despercebidas a princípio, tomando outra dimensão nas escritas. Em outro momento, Luna nos diz a respeito da dinâmica da caixa mágica, realizada com as crianças, em que, sem saber, veriam a própria imagem refletida no espelho que estava dentro da caixa rosa de papel:

Cada um/a olhava a imagem dentro da caixa para dizer por que aquela pessoa é importante e uma qualidade delela. Algumas das respostas foram alegre, feia, ruim, não sei. Ainda surpresa com algumas das respostas, [...] fui provocada por 
uma das crianças a também olhar para dentro da caixa e falar sobre mim. Disse que tenho muitas esperanças [...]. (Diário de bordo, Luna Laís, agosto 2019).

Novamente, a atenção flutuante discutida por Barros e Kastrup (2015) se interpõe nesses processos, ao lidarmos no momento da realização das atividades com uma explosão de narrativas que nos atravessam e que ganham outras potências no retorno ao que foi registrado no diário de bordo; isso, implicado aos laços e maleabilidade do pesquisador/cartógrafo frente às narrativas e subjetividades que emergiram/emergem no processo. Aqui as subjetividades são produzidas, os sujeitos são ficcionais e mutantes, produzem desejos, como nos afirma em sala de aula a supervisora de Estágio, prof. a Ana Lúcia, quando narra sobre um trecho das suas observações registradas em campo, no seu diário de bordo, ao observar as aulas do Estágio acerca das produções de subjetividade das crianças, ao afirmar:

[...] As crianças ao perceberem a minha chegada [Prof. ${ }^{a}$ Ana Lúcia, para observar as aulas] encontravam estratégias próprias e apropriadas de sentarem próximos dela e pedir que as deixassem usar o iphone para fazerem as selfies deles/as e com os colegas, e das apresentações dos grupos realizando algumas atividades. Pousavam para a foto, criavam, manipulavam e espetacularizavam, produzindo invenções de si e do outro. (Diário de bordo, Ana Lúcia setembro, 2019).

Capturas do instante, do aqui e agora como potência, sujeitos dotados de vontade, falando e agindo através de uma multiplicidade, mesmo que seja na pessoa que fala e age, acionam desejos de se enxergarem nas fotos, com suas faces e engenhosas poses e risos, numa relação de poder (des)centrada, autônoma e soberana entre pares, numa horizontalidade movida não pela representação, mas pela ação das subjetivações produzidas. Potência em ação, em devir.

Fomos forçados a fazer o movimento que Deleuze (2012, p. 100) nos apresenta no seu livro Empiria e subjetividade, ao dizer: [...] "o sujeito ${ }^{5}$ reflete e se reflete; daquilo que o afeta em geral, ele extrai um poder independente do exercício atual, isto é, uma função pura e ultrapassa sua parcialidade própria.[...] É esta a dupla potência da subjetividade: crer e inventar, ser artificioso.” Há nesse movimento uma polifonia inerente à pesquisa implicada com o Outro. As vozes das crianças e adolescentes, dos/as cartógrafos/as, ambas construindo e produzindo agenciamentos coletivos.

Narrativas que trazem à tona o que vemos, ouvimos e sentimos. Daí percebemos que também estamos a nos autocartografar, ao nos (re)conhecer como seres em processo, em devir. Barros e Kastrup (2015, p. 73) ainda nos lembram que "a processualidade se faz presente nos avanços e nas paradas, em campo, entre letras e linhas, na escrita, em nós [...]. $\mathrm{O}$ acompanhamento de tais processos depreende de uma atitude, de um ethos, e não está garantida de antemão" (BARROS; KASTRUP, 2015, p. 73).

O que se percebe, é que também pela palavra mergulhamos e atravessamos a nós mesmas, entre medos e desejos. Tecendo narrativas de si quando nos (re) construímos a partir das relações e ligações com o outro. O que nos leva a reflexões singulares. Somos quem somos porque nos constituímos nas relações com o outro, que é diverso. Fazendo ver as relações

\footnotetext{
${ }^{5}$ Mesmo utilizando o termo sujeito, usa como dissolução da noção moderna de sujeito, toma a subjetividade como processo maquínico, transitando da ideologia para a subjetivação, dos processos representacionais para os processos maquínicos. Sujeito como forma e não como essência. Resistir ao ato de identificar cada sujeito, grudar nele uma identidade bem-conhecida e bem-determinada. As formas-sujeito: sujeito como algo produzido, fabricado, modelado, consumido. Forma cambiante, mutante, relacional, uma subjetividade multifacetada. Resistência a uma subjetividade capitalista que, investe na mesmidade individualizada, reafirma, por sua vez, a possibilidade da diferença, da variação, da metamorfose, para tensionar a identidade.
} 
sociais nas quais estamos inseridos, em meio a uma sociedade imbricada em poderes que solidificam tantos preconceitos, apreendidos desde a infância. (Des)construir é processo contínuo, e foi essa uma das motivações que provocaram a realizar nos estágios atividades que discutam e problematizem as "verdades" que nos são apresentadas e cristalizadas nos processos escolares e não escolares. Há aqui, a variação potente que o dispositivo diário de bordo, nos permitiu capturar, fazer ver e falar, desembraçando linhas, vazando a diferença.

Por essas vias nos concebemos como cartógrafos/pesquisadores/as, mas também como sujeitos afetados por histórias que tecem o outro no mundo. Tecem a diversidade de classe, gênero, raça, sexualidade, situação socioeconômica, dentre outros fatores que se intercruzam, pelas vias da interseccionalidade, como afirma Akotirene (2019). Fazendo ver que as (des)territorialidades são possíveis e acontecem de modo ímpar em ações que aparentemente pequenas, ganham dimensões que não ousávamos antes imaginar possíveis:

[...] com desenhos e relatos escritos das crianças e adolescentes, destacaram, por exemplo, que: "Aprendi que não pode ter racismos e julgar aparências" $e$ "Aprendemos a importância de ser negro. Assim, percebemos que houve mudanças no grupo a partir das atividades desenvolvidas, provocando-os a questionar padrões e estereótipos construídos socialmente". (Diário de Bordo da estagiária Luna Laís, setembro de 2019).

A polifonia de vozes que se intercruzam no processo cartográfico metaforiza o rizoma. Nele não se sabe onde começam ou onde terminam as narrativas e subjetividades, mas como elas se encontram, entram em conflito e tecem outros caminhos através dos fios de sua existência e experiências. Foram nesses trânsitos que potencializamos o Estágio Supervisionado, que se desdobra, transcende e deixa de ser apenas um componente curricular ou pré-requisito acadêmico, para se desdobrar nas vias da descoberta dos estagiários e suas relações com o outro nos modos de ser e estar na docência em devir.

\section{Considerações finais}

Atravessados pela escuta e leitura das experiências e afetamentos que a cartografia e seus movimentos provocaram em mim e nos meus estudantes de graduação, ainda tão jovens, e coautores deste texto, e, da experiência de Estágio Supervisionado, habitamos parte dos espaços institucionais, como a universidade, que no geral pela sua lógica moderna, refuga, escanteia, a experiência por não considerar a mesma, importante na produção do conhecimento científico moderno, cuja racionalidade mercantiliza o conhecimento, na universidade-fábrica, colocando-a na ordem do mercado e da homogeneização este movimento de identificar-referenciar, moveu-me para tensionar, problematizar, mais que responder a pergunta lançada: O que pode um Estágio Supervisionado? Como afetar estudantes e convidar a habitar outros modos da formação docente? A experiência se dá sempre com, com o que nos passa, nos toca, nos afeta, no encontro com o outro, como a-contecimento.

Mergulhados na experiência que nos tocou, nos afetou, produzimos este texto, cuja tecitura de vozes polifônicas ora mais densas, ora mais fluidas, nos forçava a pensar, a realizar voos e experimentos nos encontros como a-contecimento

$\mathrm{Na}$ cartografia, começamos não pelo cognitivo, mas pelas sensações fugidias, que nos escapam aos nossos olhares e nos convidam a aprender a olhar, observar, tatear, pelas andanças no território, a fim de acompanhar os processos e a produção de subjetividades no território habitado, que não é o seu, que desconhecem e para onde se movem, a fim de produzirem paisagens-territórios colocando seus corpos e olhos, portanto, corpos paisagens-territórios autorais. 
A cartografia nos ensina que nossas questões não vêm apenas de nossas cabeças, mas que questionamos na medida em que estabelecemos relações com aquilo que nos faz questionar. Dito de outra forma: Indaguei-me e indaguei aos meus estudantes como intercessores, sobre a universidade e em especial sobre a formação de professores/as-pesquisadores/as e quais poderiam ser as contribuições do método da cartografia para esta formação, na medida em que produzi o encontro com a cartografia, como exercício do pensamento nas aulas de Estágio Supervisionado.

Por isso, sem entrar em contato com as coisas, para que as coisas nos façam pensar, nos forcem a pensar, e sair do lugar, se deslocar, não se aproxima da cartografia. Mas não é qualquer deslocamento, por isto é tão desafiador: é um deslocamento das ideias prontas e naturalizadas, do que parece ser assim mesmo, parece estar lá desde sempre e não tem como mudar. "Cartografar é fazer a leitura do social, do psicossocial, desde o desejo; fazer a passagem do desejo ao político, nos quadros e modos de subjetivação". (GUATTARI; ROLNIK, 2013, p. 13-19). Caso não seja este seu objetivo ao pesquisar, ensinar, não se demore na cartografia, busque outros métodos, estratégias, pois esta escolha pela cartografia implica em quedas, desassossegos, aventuras, fundo sem fundo, incertezas, apaixonamentos, constantes problematizações e desconfianças.

Exige de nós a clareza de que os saberes de cada área são insuficientes quando se cartografa territórios, pois ao adotarmos as micropolíticas como estratégias da economia do desejo no campo social, "devires minoritários", defendemos que o pensamento de Deleuze se apresenta como inseparável de uma política menor ${ }^{6}$, pois se trata de uma invenção de estratégias para a constituição de novos territórios, outros espaços de vida e de afeto, uma busca de saídas, desvios, arrombamentos, protestos, outros espaços de vida e de afeto, uma busca de saídas para territórios sem saída.

\section{Referências}

AKOTIRENE, C. Interseccionalidade. Coleção Feminismos Plurais (Coordenação de Djamila Ribeiro). São Paulo: Pólen, 2019.

ALMEIDA, F. S. de. Experiência e memória: narrativa e construção da modernidade em Walter Benjamin. In: ALMEIDA, F. S. de; AIDAR, Adriana Marques. Condição humana na modernidade. Uberaba: Universidade de Uberaba, 2020. p. 8-12.

BARROS, L. P. de; PASSOS, E. Diário de Bordo de Uma Viagem-Intervenção. In: KASTRUP, V.; PASSOS, E.; ESCÓSSIA, L. da. (Org.). Pistas do método da cartografia: pesquisa intervenção e produção de subjetividade. Porto Alegre: Sulina, 2015. p. 172-200.

BARROS, L. P. de; KASTRUP, V. Cartografar é acompanhar processos. In: KASTRUP, V.; PASSOS, E.; ESCÓSSIA, L. da. (Org.). Pistas do método da cartografia: pesquisa intervenção e produção de subjetividade. Porto Alegre: Sulina, 2015. p. 52-75.

DELEUZE, G.; GUATTARI, F. Mil Platôs: capitalismo e esquizofrenia. vol. 5. Rio de Janeiro: Ed. 34, 1997.

\footnotetext{
${ }^{6}$ Como nos apontam os autores é preciso que não confundamos "minoritário", que remete aos afectos, "enquanto devir ou processo", com "minoria", que indica um conjunto ou estado político-social estabelecido, mesmo que muitas vezes oprimido. Cf, v. 4 Mil Platôs para aprofundamento e o artigo "Dimensões políticas da teoria deleuziana dos signos" registrada nas referências finais.
} 
DELEUZE, Gilles. Empirismo e subjetividade: ensaio sobre a natureza humana segundo Hume. Tradução de ORLANDI, Luiz B. L. Rio de Janeiro: Editora 34. p. 168.

FOUCAULT, M. Microfísica do Poder. Rio de Janeiro: Graal, 1979.

GUATTARI, Félix. Revolução molecular: pulsações políticas do desejo. 2. ed. São Paulo: Brasiliense, 1985.

GUATTARI, Félix; ROLNIK, Suely. Micropolítica: cartografias do desejo. 11. ed. Petrópolis: Vozes, 2013.

GUATTARI, Félix. Da produção da subjetividade. In: Caosmose: um novo paradigma estético. Rio de Janeiro: Editora 34, 1992.

JOSSO, M. C. A transformação de si a partir da narração de histórias de vida. Educação, Porto Alegre/RS, ano XXX, n. 3 (63), p. 413-438, set./dez. 2007.

KASTRUP, V.; BARROS, R. B. de. Movimentos-funções do dispositivo na prática da cartografia. In: KASTRUP, V.; PASSOS, E.; ESCÓSSIA, L. da. (Org.). Pistas do método da cartografia: pesquisa-intervenção e produção de subjetividade. Porto Alegre: Sulina, 2015. p. 76-91.

NASCIMENTO, Roberto Duarte de. Dimensões políticas da teoria deleuziana dos signos. In: GALLO, Sílvio; NOVAES, Marcus; GUARIENTI, Laisa B. de Oliveira (Org.). Conexões: Deleuze e Política e Resistência e... Campinas: SP, ALB; Brasília, DF: CAPES, 2013.

\section{Sobre os autores}

Ana Lúcia Gomes da Silva. Pós-doutora em Educação pela Universidade Federal do Triângulo Mineiro - UFTM, Doutora e Mestre em Educação (Universidade Federal da Bahia - UFBA). Professora titular do Departamento de Ciências Humanas - Campus IV, Jacobina, da Universidade do Estado da Bahia (UNEB). Líder do grupo de pesquisa Diversidade, Discursos, Formação na Educação Básica e Superior (DIFEBA).

E-mail: analucias12@gmail.com.

Luciano Santos Xavier. Graduado em Letras, Língua Portuguesa e Literaturas, pela Universidade do Estado da Bahia (UNEB) - DCH - Campus IV - Jacobina/BA. Integrante do Grupo de Pesquisa Linguagem, Estudos Culturais e Formação do Leitor (LEFOR).

E-mail: lu.ciano2011@live.com.

Luna Layse Almeida da Silva. Bacharela em Comunicação Social com Habilitação em Jornalismo em Multimeios pela Universidade do Estado da Bahia (UNEB) - DCH - Campus III - Juazeiro/BA e graduanda em Letras, Língua Portuguesa e Literaturas, pela UNEB - DCH - Campus IV - Jacobina/BA. Integrante do grupo de pesquisa Diversidade, Discursos, Formação na Educação Básica e Superior (DIFEBA).

E-mail: lunalayse@hotmail.com. 